\title{
Receptores de Estrógeno e Progesterona em Células do Sedimento de Fluido Peritoneal na Endometriose Pélvica: Estudo Imunocitoquímico
}

\author{
Estrogen and Progesterone Receptors in Peritoneal Fluid Cell Sediment in \\ Pelvic Endometriosis: Immunocytochemical Study
}

José Eleutério Junior, Diane Isabelle Magno Cavalcante, Francisco Valdeci de Almeida Ferreira Francisco das Chagas Medeiros

\begin{abstract}
RESUMO
Objetivo: avaliar a expressão de receptores de estrógeno (RE) e progesterona (RP) em esfregaços de sedimento de fluido peritoneal em pacientes com endometriose, comparandoa com a de mulheres sem endometriose.

Métodos: foi realizado imunocitoquimica para $R E$ e RP em esfregaços de sedimento de fluido peritoneal em 19 casos de endometriose e 7 sem endometriose (controle). Os dados foram submetidos ao teste t de Student para análise estatística.

Resultados: em 84,6\% dos casos de pacientes com endometriose, células tipo endometrial expressaram RE, numa média de 4,1\%, ao passo que nos casos sem endometriose foi positivo em 42,9\%, com uma expressão média de 4,5\% ( $p=0,1706)$. RP foi expresso apenas em um caso, com endometriose, com história de rotura de endometrioma.

Conclusões: não houve diferença da expressão de RE entre os casos de endometriose e os casos-controle, observando-se um comportamento distinto em tecidos. Um mais aprofundado estudo deve ser feito para melhor avaliar o enigmático mecanismo envolvido na manifestação de receptores hormonais em células esfoliadas.
\end{abstract}

PALAVRAS-CHAVE: Endometriose. Receptores de estrógeno. Receptores de progesterona. Imunocitoquimica.

\section{Introdução}

A presença de receptores de estrógeno $(\mathrm{RE})$ e de progesterona (RP) tem sido documentada tanto no endométrio ${ }^{1-5}$ como em tecido endometriótico $^{6,7}$.

Vários métodos têm sido utilizados para identificar receptores esteróides em endométrio e focos endometrióticos. No entanto, a técnica imunohistoquímica usando anticorpos monoclonais específicos para RE e RP tem a vantagem de requerer pequena quantidade de tecido ${ }^{7}$ que pode ser fixado e incluído em parafina, além de esfregaços citológicos.

Usando anti-receptores específicos, os investigadores têm estudado a presença e expressão de

Departamento de Patologia e Medicina Legal e Departamento Materno-infantil da Universidade Federal do Ceará.

Correspondência: José Eleutério Junior

Rua Barão de Aracati, 450 - Meireles

60115-080 - Fortaleza - Ceará
RE e RP, por imuno-histoquímica, no endométrio durante do ciclo menstrual ${ }^{2,8}$. O conteúdo de RE cai durante a fase secretória tanto em células estromais quanto em glandulares. No entanto, o conteúdo de RP diminui essencialmente nas células glandulares durante a fase secretória ${ }^{8}$.

$\mathrm{Na}$ endometriose peritoneal e ovariana, a regulação hormonal é diferente da endometrial e receptores de progesterona são sintetizados, mas não são completamente ativos biologicamente ${ }^{7}$. Portanto, nas lesões endometrióticas o achado de uma atividade proliferativa persistente nas fases secretória e menstrual poderia ser explicado pela falha na expressão do receptor de progesterona que suprimiria tal proliferação ${ }^{7}$.

Assim, em endométrio ectópico, a ausência de alterações morfológicas durante a fase secretória, a persistência de atividade mitótica no período que vai do meio da fase secretória à fase proliferativa tardia e a persistência de RP em células glandulares durante a fase secretória tardia 
sugerem uma relativa independência hormonal, ou pelo menos a existência de um mecanismo diferente do controle fisiológico de proliferação ${ }^{7}$.

O objetivo deste trabalho foi observar a expressão de receptores de estrógeno e progesterona, em grupamentos celulares com caracteristicas endometriais, em sedimento de fluido peritoneal de pacientes com endometriose pélvica, comparando com material de pacientes sem endometriose.

\section{Pacientes e Métodos}

Foi realizado estudo retrospectivo de 26 esfregaços citológicos confeccionados a partir de sedimento de fluido peritoneal colhido durante procedimento de videolaparoscopia para investigação de infertilidade. Desses esfregaços, 19 eram de casos de endometriose, com confirmação histopatológica, e 7 tiveram outros diagnósticos, sendo considerados como grupo controle.

A média de idade das pacientes do grupo endometriose $(\mathrm{n}=19)$ foi de 31,5 anos e do grupo controle $(\mathrm{n}=7$ ) foi de 32,2 anos. As laparoscopias de forma rotineira eram realizadas na primeira fase do ciclo menstrual, com exceção de um caso de rotura aguda de endometrioma.

Os esfregaços fixados em álcool a 95\% foram submetidos a recuperação antigênica em microondas (15 min, $650 \mathrm{~W}$ em tampão citrato), em seguida incubados com anticorpo monoclonal para receptor de estrógeno (clone ER ID5, Dako) e receptor de progesterona (clone PgR636, Dako) por 14 horas em câmara úmida. A revelação foi feita com complexo peroxidase-antiperoxidase (PAP).

Nos esfegaços foram observados os percentuais de núcleos marcados ( $\mathrm{RE}$ e RP), portanto corados em marrom, em células com características citomorfológicas de origem endometrial, em uma contagem mínima de 200 células por esfregaço. A análise foi feita em microscópio óptico, utilizando videomicroscópio com câmera de marca Samsung acoplada a microscópio Nikon triocular, com placa de captura de imagem e vídeo, em computador com placa Intel tipo KII 66. Todas as análises foram realizadas utilizando-se aumentos de 400 e 1000 vezes. Foi utilizado o teste $t$ de Student para significância estatística.

O projeto de pesquisa foi apreciado e aprovado pelo Comitê de Ética em Pesquisa da instituição.

\section{Resultados}

Das 19 pacientes com diagnóstico de endometriose, a presença de grupos celulares com características endometriais ocorreu em 13 casos $(68,4 \%)$. A marcação para RE ocorreu em $84,6 \%$ dos esfregaços dessas pacientes, com expressão variando entre 0,5 e 16,4\% das células, com uma média de $4,1 \%$ e desvio-padrão da média de 1,4\%, ao passo que nos casos-controle havia grupamentos característicos de células endometriais em todos os casos, com marcação para $\mathrm{RE}$ em apenas 3 casos (42,9\%), variando de 0,5 a $6,8 \%$, com uma média de $4,5 \%$ e um desviopadrão da média de 1,3\% (Figura 1). Utilizando o teste $t$ de Student obteve-se um p de 0,17, o que indica não haver diferença significante nos dados apresentados (Figura 2).

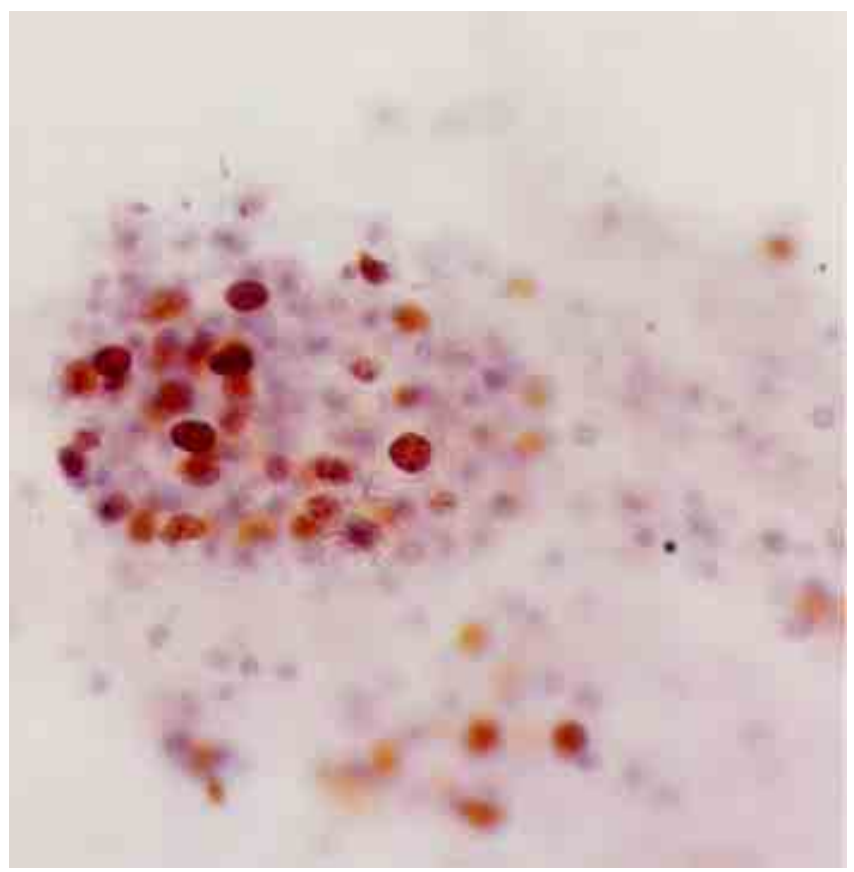

Figura 1 - Expressão de RE (receptor de estrógeno) em células do tipo endometrial de esfregaço de fluido peritoneal de paciente com endometriose pélvica

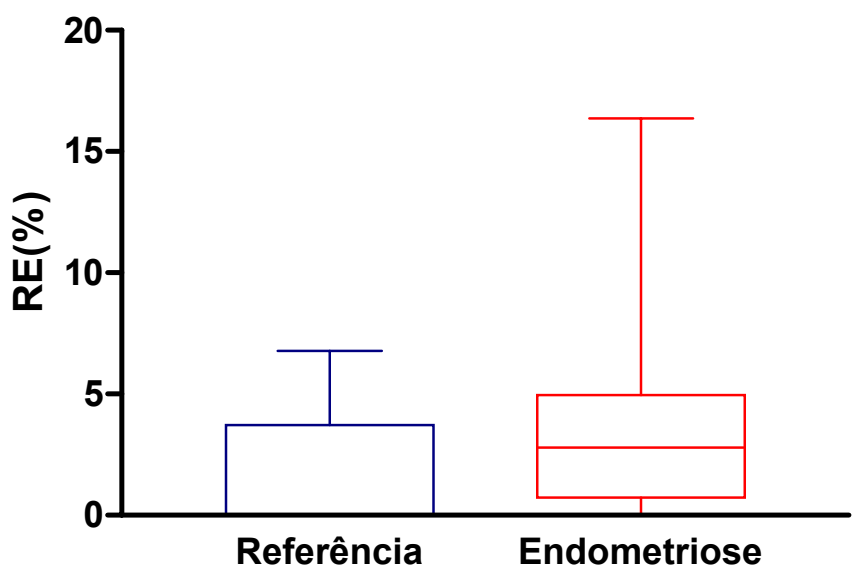

Figura 2 - Expressão de RE (receptor de estrógeno) em células tipo endometrial de esfregaços de fluido peritoneal em pacientes com endometriose $(n=13)$ e grupo de referência $(n=7)$. 
Os RP foram expressados em apenas um caso de paciente portadora de endometriose, cujo procedimento laparoscópico havia sido realizado de urgência por rotura de endometrioma. A expressão fraca ocorreu em $1,7 \%$ dos elementos celulares com características endometriais.

\section{Discussão}

O estudo de receptores de estrógeno (RE) e de progesterona (RP) pela técnica de imunohistoquímica usando anticorpos monoclonais especificos tem a vantagem de requerer só uma pequena quantidade de tecido ${ }^{7}$. Diferentemente da análise em tecidos, nos quais uma organização arquitetural permite uma precisa identificação do tipo celular que expressa os receptores, o esfregaço de sedimento de fluido peritoneal exibe grupos de células com provável origem glandular, que podem ter entremeadas células estromais também com capacidade de expressão de tais receptores. No entanto, mais do que o tipo de célula específico, importa a origem do grupamento, se do tipo endometrial, ou com outras características. Para efeito do estudo foram analisadas apenas células com características citomorfológicas sugestivas de origem glandular endometrial.

Nos casos do grupo controle, RE estavam presentes em 42,9\%, com indice de positividade média de $4,5 \%$, e no grupo com endometriose, em $84,6 \%$ dos casos, com indice de positividade média de $4,1 \%$. Jänne et al. ${ }^{6}$ encontraram em tecidos a presença de RE em 40\% dos espécimes, ao passo que Nisolle e Donnez ${ }^{7}$ observaram uma maior expressão dos receptores na fase proliferativa em biópsias de mulheres com endometriose. Embora o índice de positividade tenha sido bastante diferente nos dois grupos, a presença de células tipo endometrial positivas para RE foi mais acentuada no grupo de pacientes com endometriose, o que sugere uma maior possibilidade de presença de células do tipo endometrial soltas na cavidade peritoneal. Essas células são potencialmente mais responsivas a algum tipo de controle hormonal, embora de forma diferente daquele até então conhecido sobre o endométrio tópico. No entanto, não houve diferença significante quanto à expressão de RE nos dois grupos, embora a expressão de RE em tecidos nos casos de endometriose tenha comportamento já definido ${ }^{6,7}$. O estudo em células esfoliadas na cavidade peritoneal não havia sido até então realizado. Por esses dados preliminares, pode-se conjeturar um comportamento distinto de células esfoliadas, que expressariam RE de forma semelhante na presença ou não da doença, embora com maior possibilidade de positividade na sua presença. Assim, parece que mecanismos mais complexos da patogênese da endometriose se envolvem nesse enigmático contexto, carecendo de estudos mais aprofundados, inclusive de outros elementos presentes nos sedimentos de fluido peritoneal.

Os RP só foram identificados em um único caso de endometriose pélvica de paciente que se apresentou com endometrioma roto e, mesmo assim, fracamente positivo. A falta de receptores de progesterona em elementos celulares de origem epitelial endometrial nesses sedimentos seria justificada pelo fato de haverem sido as laparoscopias todas realizadas no início da primeira fase do ciclo? Comparando-se com estudo em tecidos, em que Nisolle et al. ${ }^{8}$ demonstraram que o conteúdo de RP em lesões endometrióticas, negras e vermelhas, foi alto na fase proliferativa do ciclo no epitélio glandular, observam-se aqui dados conflitantes quando comparados esfregaços citológicos com o estudo histológico. Seriam aspectos relacionados à descamação dos grupamentos epiteliais em um meio peritoneal, de forma mais ou menos crônica, responsável por este comportamento anômalo? Estariam tais células menos expostas a estímulos para a expressão de tais receptores de progesterona? Há de se aprofundar o estudo e aumentar o número de casos observados para se ter uma melhor noção dos complexos mecanismos que aqui podem estar envolvidos.

Assim, a pesquisa de receptores hormonais (RE e RP) em esfregaços citológicos, em quadros de endometriose, em termos de expressão, parece ser de pouca valia no estudo da endometriose, embora traga questionamentos que estimulam mais pesquisas de uma doença que parece ter manifestações variadas e complexas conforme a metodologia. Obviamente que um maior número de casos estudados e ampliação de elementos avaliados podem trazer novas observações que ajudem a compreender sua patogênese.

\section{SUMMARY}

Purpose: to evaluate the expression of estrogen (ER) and progesterone $(P R)$ receptors in smears of peritoneal fluid sediment from patients with and without endometriosis.

Methods: immunocytochemical study of ER and PR in smears of peritoneal fluid sediment in 19 cases with endometriosis and 7 without (control group), observing their expression. The data were submitted to Student's t-test to evaluate statistical significance.

Results: in $84.6 \%$ of the cases with endometriosis, 
endometrial-like cells expressed ER (mean $=4.1 \%)$. In cases without endometriosis there was ER expression in $42.9 \%$, with a mean of $4.5 \%(p=0.1706)$. PR was expressed in only one case of endometriosis, with an endometrioma rupture history.

Conclusions: there was no difference of ER expression between cases with endometriosis and the control group, in contrast to tissue behavior. Further cases must be studied for a better evaluation of this enigmatic mechanism of hormonal receptors in exfoliated cells.

KEY WORDS: Endometriosis. Receptors, estrogen and progesterone, peritoneal fluid cells. Immunocytochemistry.

\section{Referências}

1. Garcia E, Bouchard P, De Brux J, et al. Use of immunocytochemistry of progesterone and estrogen receptors for endometrial dating. J Clin Endocrinol Metab 1988; 67:80-7.

2. Press MF, Udove JA, Green GL. Progesterone receptor distribution in the human endometrium: analysis using monoclonal antibodies to the human progesterone. Am J Pathol 1988; 131:112-24.
3. Snijders MP, De Goeij AF, Debets-Te Baerts MJ, Rousch MJ, Koudstaal J, Bosman FT. Immunocytochemical analysis of oestrogen and progesterone receptors in the human uterus throughout the menstrual cycle and after the menopause. J Reprod Fertil 1992; 94:363-71.

4. Tamaya T, Motoyama T, Ohono Y, Ide N, Tsurusaki $\mathrm{T}$, Okada H. Steroid receptor levels and histology of endometriosis and adenomyosis. Fertil Steril $1979 ; 31: 396-400$.

5. Tamaya T, Muramaki T, Okada H. Concentrations of steroid receptors in normal human endometrium in relation to the day of the menstrual cycle. Acta Obstet Gynecol Scand 1986; 65:195-8.

6. Jänne O, Kauppila A, Kokko E, Lantto T, Rönnberg L, Vihko R. Estrogen and progestin receptors in endometriosis lesions: comparison with endometrial tissue. Am J Obstet Gynecol 1981; 141:562-6.

7. Nisolle M, Donnez J. Peritoneal, ovarian and rectovaginal endometriosis: the identification of three separate diseases. $1^{\text {st }}$ ed. Carnforth: Parthenon; 1997. p.280.

8. Nisolle M, Casanas-Roux F, Wyns C, De Menten Y, Mathieu PE, Donez J. Immunohistochemical analysis of estrogen and progesterone receptors in endometrium and peritoneal endometriosis: a new quantitative method. Fertil Steril 1994; 62:751-9. 